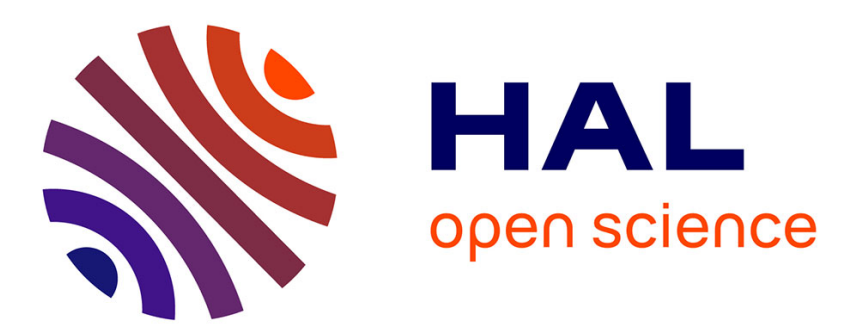

\title{
Chemical vapor deposition of low reflective cobalt (II) oxide films
}

Eliane Amin-Chalhoub, Thomas Duguet, Diane Samélor, Olivier Debieu, Elisabeta Ungureanu, Constantin Vahlas

\section{To cite this version:}

Eliane Amin-Chalhoub, Thomas Duguet, Diane Samélor, Olivier Debieu, Elisabeta Ungureanu, et al.. Chemical vapor deposition of low reflective cobalt (II) oxide films. Applied Surface Science, 2016, 360, pp.540-546. 10.1016/j.apsusc.2015.10.188 . hal-01264368

\section{HAL Id: hal-01264368 https://hal.science/hal-01264368}

Submitted on 4 Mar 2016

HAL is a multi-disciplinary open access archive for the deposit and dissemination of scientific research documents, whether they are published or not. The documents may come from teaching and research institutions in France or abroad, or from public or private research centers.
L'archive ouverte pluridisciplinaire HAL, est destinée au dépôt et à la diffusion de documents scientifiques de niveau recherche, publiés ou non, émanant des établissements d'enseignement et de recherche français ou étrangers, des laboratoires publics ou privés. 


\section{Open Archive TOULOUSE Archive Ouverte (OATAO)}

OATAO is an open access repository that collects the work of Toulouse researchers and makes it freely available over the web where possible.

This is an author-deposited version published in : http://oatao.univ-toulouse.fr/ Eprints ID : 14628

To link to this article : DOI : 10.1016/j.apsusc.2015.10.188

URL : http://dx.doi.org/10.1016/j.apsusc.2015.10.188

To cite this version : Amin-Chalhoub, Eliane and Duguet, Thomas and Samélor, Diane and Debieu, Olivier and Ungureanu, Elisabeta and Vahlas, Constantin Chemical vapor deposition of low reflective cobalt (II) oxide films. (2016) Applied Surface Science, vol.360. pp.540-546. ISSN 0169-4332

Any correspondance concerning this service should be sent to the repository administrator: staff-oatao@listes-diff.inp-toulouse.fr 


\title{
Chemical vapor deposition of low reflective cobalt (II) oxide films
}

\author{
Eliane Amin-Chalhoub, Thomas Duguet*, Diane Samélor, Olivier Debieu, \\ Elisabeta Ungureanu, Constantin Vahlas \\ CIRIMAT, CNRS - Université de Toulouse, 4 allée Emile Monso, BP-44362, 31030 Toulouse Cedex 4, France
}

\begin{abstract}
A B S T R A C T
Low reflective $\mathrm{CoO}$ coatings are processed by chemical vapor deposition from $\mathrm{Co}_{2}(\mathrm{CO})_{8}$ at temperatures between $120^{\circ} \mathrm{C}$ and $190^{\circ} \mathrm{C}$ without additional oxygen source. The optical reflectivity in the visible and near infrared regions stems from 2 to $35 \%$ depending on deposition temperature. The combination of specific microstructural features of the coatings, namely a fractal "cauliflower" morphology and a grain size distribution more or less covering the near UV and IR wavelength ranges enhance light scattering and gives rise to a low reflectivity. In addition, the columnar morphology results in a density gradient in the vertical direction that we interpret as a refractive index gradient lowering reflectivity further down. The coating formed at $180^{\circ} \mathrm{C}$ shows the lowest average reflectivity (2.9\%), and presents an interesting deep black diffuse aspect.
\end{abstract}

Optical reflectivity

MOCVD

Refractive index gradient

$\mathrm{CoO}$

Cobadkide

\section{Introduction}

Low reflectivity films are used in optical instruments and sensors with the aim to attenuate noise, namely to reduce the effect of stray and scattered light in different spectral domains [1]. Such films find applications in military night sight for optical guidance systems [2], in space applications [3] and can also be used for heat dissipation between different components in microelectronic devices [4]. Moreover, light absorber films are used in the renewable energy domain in photothermal energy conversion [5-8], in photoelectric energy conversion [9], and in solar thermophotovoltaic conversion systems [10-12].

Black coatings are spread over a large variety of materials in the families of metals, alloys, ceramics, and polymers $[5,6,13]$. Among them, the cobalt (II, III) oxide $\mathrm{Co}_{3} \mathrm{O}_{4}$ exhibits high optical absorbance which is appropriate for solar absorbers for photothermal conversion [14]. Indeed, $\mathrm{Co}_{3} \mathrm{O}_{4}$ presents spectrally selective surfaces exhibiting high values of solar absorbance $(\alpha)$ in the visible and the near infra-red (NIR) spectrum and low values of thermal emittance $(\varepsilon)$ in the IR spectrum which improves their thermal performance by reducing the radiative heat loss component. Moreover, in contrast to chromium based black coatings, Co-based ones maintain acceptable values of $\alpha$ and $\varepsilon$ even after exposure to air $(1000 \mathrm{~h}$ at $\left.650^{\circ} \mathrm{C}[15]\right)$.

\footnotetext{
Corresponding author. Tel.: +33 534323439

E-mail addresses: thomas.duguet@ensiacet.fr, doug181@gmail.com (T. Duguet).
}

Co oxide films are obtained by wet processes such as thermal decomposition, electrodeposition [14,16,17] and sol-gel [18]. Dry processes are also employed such as PVD [19,20], ALD [21-24] and metalorganic CVD (MOCVD) [25-28]. Several authors use MOCVD to grow cobalt oxide films. Fuji et al. formed Co oxide films by plasma enhanced MOCVD (PEMOCVD). They obtain CoO films at low oxygen flow rate with a surface morphology in the form of packed columnar grains. Increasing the oxygen flow rate leads to the formation of columnar $\mathrm{Co}_{3} \mathrm{O}_{4}$ films within the same temperature range $\left(400^{\circ} \mathrm{C}\right)$ [29]. Similar observations are mentioned by Tyezkowski et al. who show that film composition is highly correlated to the $\mathrm{O}_{2}$ molar fraction. Films are composed essentially of $\mathrm{Co}_{3} \mathrm{O}_{4}$ with the presence of carbon and amorphous $\mathrm{CoO}_{x}$ at low $\mathrm{O}_{2}$ flow rate [25]. Mane and Shivashankar similarly obtained by MOCVD dense and continuous $\mathrm{Co}_{3} \mathrm{O}_{4}$ films with a packed grains morphology when using $\mathrm{O}_{2}$, but porous films composed of a mixture of $\mathrm{Co}_{3} \mathrm{O}_{4}$ and $\mathrm{CoO}$ while using $\mathrm{N}_{2} \mathrm{O}$ [30]. $\mathrm{Co}_{3} \mathrm{O}_{4}$ films are grown as well by Direct Liquid Injection (DLI-) MOCVD under a working pressure of 5 Torr but at temperatures higher than ours: $350-600^{\circ} \mathrm{C}$ [26]. Authors notice that while increasing deposition temperature, the film morphology varies depending on the substrate type. Film roughness increases in the case of $\mathrm{LaAlO}_{3}$ substrate while it decreases in the case of sapphire and $\mathrm{MgO}$; an interesting way for tailoring the microstructure of Co oxide films.

Finally, different MOCVD precursors can be used in order to obtain Co oxide films, such as tricarbonyl nitrosyl [27], dicarbonyl cyclopentadienyl cobalt [31], Cobalt (II) b-diketonate adducts [26], and Cobalt (II) acetylacetonate [30]. In particular, dicobalt octacarbonyl $\left(\mathrm{Co}_{2}(\mathrm{CO})_{8}\right)$ is used to process films at low temperature 
Table 1

MOCVD process parameters used for the deposition of cobalt oxide films.

\begin{tabular}{ll} 
Deposition temperature $\left({ }^{\circ} \mathrm{C}\right)-T_{\mathrm{d}}$ & $120-190$ \\
Precursor temperature $\left({ }^{\circ} \mathrm{C}\right)$ & 27 \\
Total pressure (Torr) & 5 \\
Saturation vapor pressure of $\mathrm{Co}_{2}(\mathrm{CO})_{8}$ (Torr) & 0.0041 \\
$\mathrm{~N}_{2}$ carrier gas flow rate $(\mathrm{sccm})$ & 30 \\
$\mathrm{~N}_{2}$ dilution gas flow rate $(\mathrm{sccm})$ & 170 \\
$\mathrm{Co}_{2}(\mathrm{CO})_{8}$ flow rate $(\mathrm{sccm})$ & $24.6 \times 10^{-3}$ \\
$\mathrm{Co}_{2}(\mathrm{CO})_{8}$ molar fraction & $1.23 \times 10^{-4}$ \\
Deposition duration $(\mathrm{min})$ & 80 \\
\hline
\end{tabular}

* Upper limit assuming full efficiency of precursor vaporization and transport.

$\left(<200^{\circ} \mathrm{C}\right)$, ultimately allowing processing thermally sensitive substrates [32-36]. The present work revisits the use of $\mathrm{Co}_{2}(\mathrm{CO})_{8}$ for the low temperature MOCVD of cobalt oxides, with following three peculiarities: (a) it investigates the thermolysis of the precursor in the absence of reactive gas, e.g. oxygen, (b) it aims at processing pure $\mathrm{CoO}$ films, (c) it focuses on the microstructure of the films. It is worth noting that such an approach has never been investigated for the MOCVD of cobalt oxides. The rationale of the work is to elaborate a process operating in a parametric window which allows processing films with stable physicochemical and microstructural characteristics and thus high performance optical properties.

The paper is organized as follows. After the experimental details section, we present and discuss the results concerning the process-structure-properties relationship. Growth rate, crystallography, composition, and morphology of the coatings are correlated with deposition temperature $\left(T_{\mathrm{d}}\right)$. Then, the optical reflectivity of the films is correlated with chemical and microstructural characteristics, namely surface roughness, grain size distribution and fractal dimension, before providing concluding remarks.

\section{Experimental details}

CVD experiments are performed in a vertical cold-wall reactor composed of a $46 \mathrm{~mm}$ diameter quartz tube. Silicon samples $\left(20 \times 10 \times 1 \mathrm{~mm}^{3}\right)$ are cut from $4^{\prime \prime} \mathrm{Si}(100)$ wafers and sonicated in acetone and ethanol baths for $5 \mathrm{~min}$, dried in an Ar flow, and baked at $60^{\circ} \mathrm{C}$ for $20 \mathrm{~min}$. They are weighted and immediately positioned flat on an inductively heated stainless steel susceptor. Deposition temperature $T_{\mathrm{d}}$ is controlled by a K-type thermocouple inserted into the core of the susceptor. Surface temperature is calibrated with an additional thermocouple attached to the surface of a dummy Si sample. Pure $\mathrm{N}_{2}$ (99.9999\%, Air Products) is used as both carrier and dilution gas and is delivered through two gas lines, thermally regulated at $35^{\circ} \mathrm{C}$, and equipped with mass flow controllers. A vane pump and pressure gauges connected to the output of the quartz tube is used to regulate the reaction pressure at 5 Torr. $T_{\mathrm{d}}$ is varied from 120 to $190^{\circ} \mathrm{C}$ in order to investigate its effect on the films morphology, composition and optical absorptivity. $\mathrm{Co}_{2}(\mathrm{CO})_{8}$ powder (Alfa Aesar, stabilized in $5 \%$ hexane) is filled into a U shaped tube, in a glove box under $99.9997 \%$ pure $\operatorname{Ar}$ (Air Products) before being connected under $\mathrm{N}_{2}$ flow with the CVD set-up. The precursor is thermally regulated at $27^{\circ} \mathrm{C}$ resulting in a saturated vapor pressure of 0.0041 Torr. Its vapor is carried with $\mathrm{N}_{2}$ leaching the surface of the powder, and then mixed with the dilution gas $\mathrm{N}_{2}$. This gas mixture is introduced from the upper part of the reactor through an $8 \mathrm{~mm}$ tube facing the substrate holder. The resulting input process conditions are listed in Table 1.

Surface morphology and roughness are measured using scanning electron microscopy (SEM) and atomic force microscopy (AFM). SEM is performed on a LEO 435VP microscope. AFM is used in ambient conditions on an Agilent Technologies 5500 instrument. Scanning is performed in contact mode with tips of spring constant

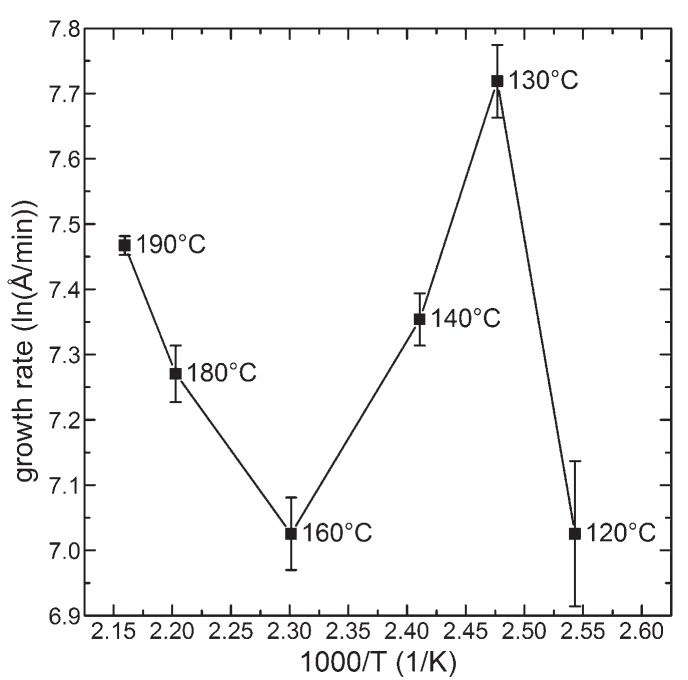

Fig. 1. Arrhenius-type plot of the growth rate of $\mathrm{CoO}$ films from $\mathrm{Co}_{2}(\mathrm{CO})_{8}$ on $\mathrm{Si}$.

of about $0.292 \mathrm{~N} / \mathrm{m}$ (AppNano). Scanning rate is $2 \mu \mathrm{m} / \mathrm{s}$. Images are processed with the software Pico Image (Agilent Technologies). Films thicknesses are measured by SEM on cross sectional micrographs at the center of each sample. Crystallographic structures are determined by X-ray diffraction (XRD) on a SEIFERT-3000TT instrument using a $\mathrm{Cu} \mathrm{K}_{\alpha}(1.5418 \AA) \mathrm{X}$-ray tube operated at $40 \mathrm{kV}$ and $40 \mathrm{~mA}$, a Ni filter and solid-state Lynxeye detector. EPMA is used to determine the elemental composition of the films (Cameca SXFive instrument). Calibration is performed using high purity standards. Each measurement is repeated five times at different locations to determine spatial homogeneity. Finally, the UV-vis-NIR total reflectivity spectra are measured by a Perkin-Elmer Lambda19 spectrophotometer equipped with an integration sphere. The reflected light is collected in the directional-hemispherical geometry with an incidence angle of $8^{\circ}$.

\section{Results and discussions}

\subsection{Growth kinetics}

Processed films systematically present a mat aspect. The color change is visually observed on the silicon substrates during the first minutes of deposition, corresponding to the upper limit of incubation time. Visual inspection of the surface facing the feeding tube reveals that films deposited at $160^{\circ} \mathrm{C}$ and $180^{\circ} \mathrm{C}$ are black, while those obtained at $120^{\circ} \mathrm{C}, 130^{\circ} \mathrm{C}, 140^{\circ} \mathrm{C}$ and $190^{\circ} \mathrm{C}$ are grey. Fig. 1 presents an Arrhenius-type plot of the global deposition reaction. Lines connecting points are guide to the eye. Growth rate fluctuates as a function of $T_{\mathrm{d}}$, increasing from 120 to $130^{\circ} \mathrm{C}$, then decreasing down to $160^{\circ} \mathrm{C}$ and finally increasing up again at higher $T_{\mathrm{d}}$. Growth rate values vary between $110 \mathrm{~nm} / \mathrm{min}$ at $T_{\mathrm{d}}=120^{\circ} \mathrm{C}$ and $160^{\circ} \mathrm{C}$, and $225 \mathrm{~nm} / \mathrm{min}$ at $T_{\mathrm{d}}=130^{\circ} \mathrm{C}$, resulting in films whose thickness varies between 9 and $18 \mu \mathrm{m}$, as measured on cross sections by SEM.

Then, the growth rate does not show an Arrhenius-type behavior. It evolves between two maxima at $130^{\circ} \mathrm{C}$ and $190^{\circ} \mathrm{C}$ and one minimum at $160^{\circ} \mathrm{C}$. This behavior has already been reported for processes involving $\mathrm{Co}_{2}(\mathrm{CO})_{8}$. While scanning a range of temperature from $50^{\circ} \mathrm{C}$ to $250^{\circ} \mathrm{C}$ at a working pressure of 0.01 Torr (which is two orders of magnitude lower than ours), Ye et al. notice two growth rate maxima at $120^{\circ} \mathrm{C}$ and $220^{\circ} \mathrm{C}$. They attribute the sharp increase of the deposition rate around $120^{\circ} \mathrm{C}$ to a possible increase of the sticking coefficient of the precursor at low temperature $[33,37]$. Then, the growth rate is likely to decrease as $T_{\mathrm{d}}$ is further increased because of homogeneous undesirable reactions [36]. In 


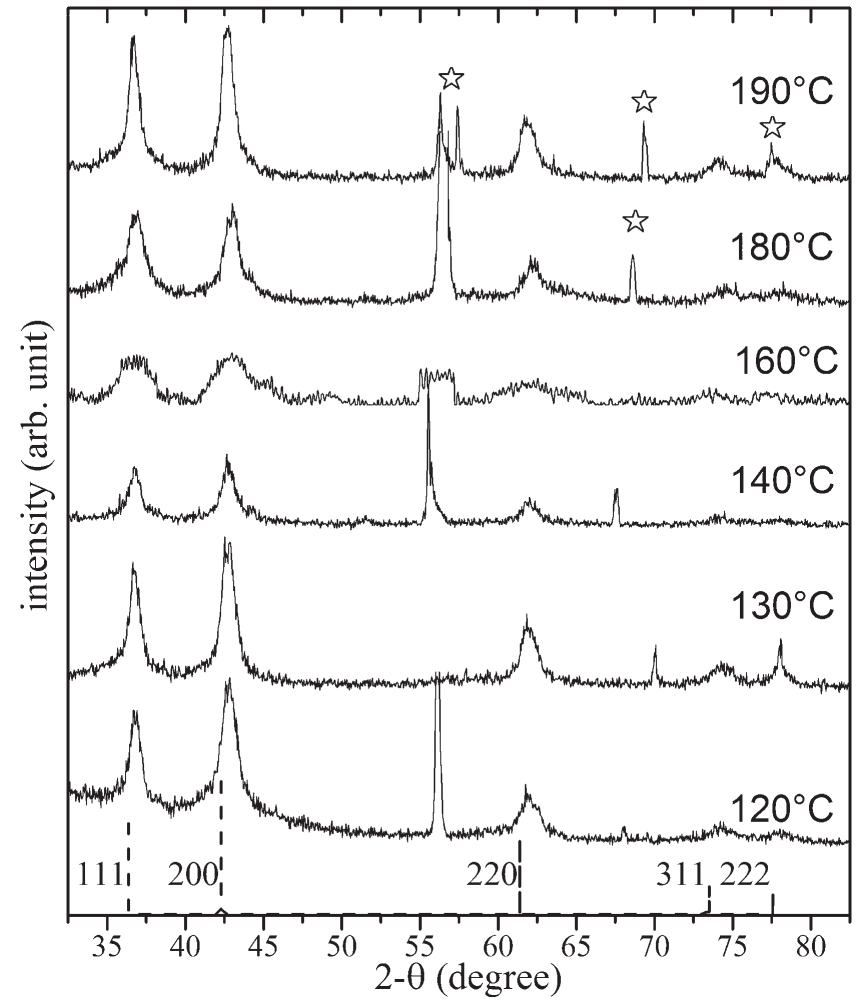

Fig. 2. XRD patterns of films processed at different $T_{\mathrm{d}}$. Stars correspond to the $\mathrm{Si}$ substrate peaks.

the same pressure range ( 0.05 Torr) and at a substrate temperature varying from $160^{\circ} \mathrm{C}$ to $280^{\circ} \mathrm{C}$, Rhee and Ahn obtain a maximum growth rate at $200^{\circ} \mathrm{C}$ [38], in good accordance with the temperatures determined in the present study $\left(190^{\circ} \mathrm{C}\right)$ and reported by Ye et al.'s $\left(220^{\circ} \mathrm{C}\right)$. Similarly, Ko et al. observed a maximum at $140^{\circ} \mathrm{C}$ $(P=0.6$ Torr) [35], in good accordance with our lowest maximum $\left(130^{\circ} \mathrm{C}\right)$ and Ye et al.'s $\left(120^{\circ} \mathrm{C}\right)$.

\subsection{Structure and morphology of the CoO films}

Fig. 2 presents X-ray diffractograms of the films processed at various temperatures. The X-ray peaks at $2 \theta$ equal $36.4^{\circ}, 42.4^{\circ}$ $61.5^{\circ}, 73.7^{\circ}$ and $77.6^{\circ}$ correspond to (111) (200), (2 20), (3 31 ) and (2 22 ) planes of the cubic cobalt oxide (II) $\mathrm{CoO}$ phase. No other cobalt oxide, namely $\mathrm{Co}_{3} \mathrm{O}_{4}$ or $\mathrm{Co}_{2} \mathrm{O}_{3}$ is revealed from the diffractograms. Films present no preferential orientation and the average crystallite diameter calculated from the Sherrer equation is estimated between $c a .100 \mathrm{~nm}$ and $150 \mathrm{~nm}$. It is concluded that all films are composed of $\mathrm{CoO}$ with no other crystalline phase. This result is corroborated with the elemental composition of the films, determined as $50 \pm 1$ at.\% Co, $50 \pm 1$ at.\% O (except at $140{ }^{\circ} \mathrm{C}$ where the composition is $47 \%$ at.\% Co, 53 at.\% O) without carbon contamination, within the detection limit of EPMA. It is interesting to recall that we obtain pure $\mathrm{CoO}$ films without introduction of any reactive gas. This precursor is generally used for the deposition of smooth metallic cobalt films at low pressure (0.03-0.2 Torr) [33-36,39]. The applied working pressure of 5 Torr in this work leads to the formation of cobalt (II) oxide. A similar result is mentioned in ref [28], where authors obtained cobalt oxide films under $\mathrm{N}_{2}$ working pressures of 2.2 and 45 Torr. Whereas they intentionally add a partial pressure of hydrogen for decreasing the amount of $\mathrm{CoO}$ in the films, they observed an increase of the amount of $\mathrm{CoO}$ from 43 to 76 at.\%! This pinpoints the complex chemistry taking place at the surface of a growing transition metal oxide film in the presence of
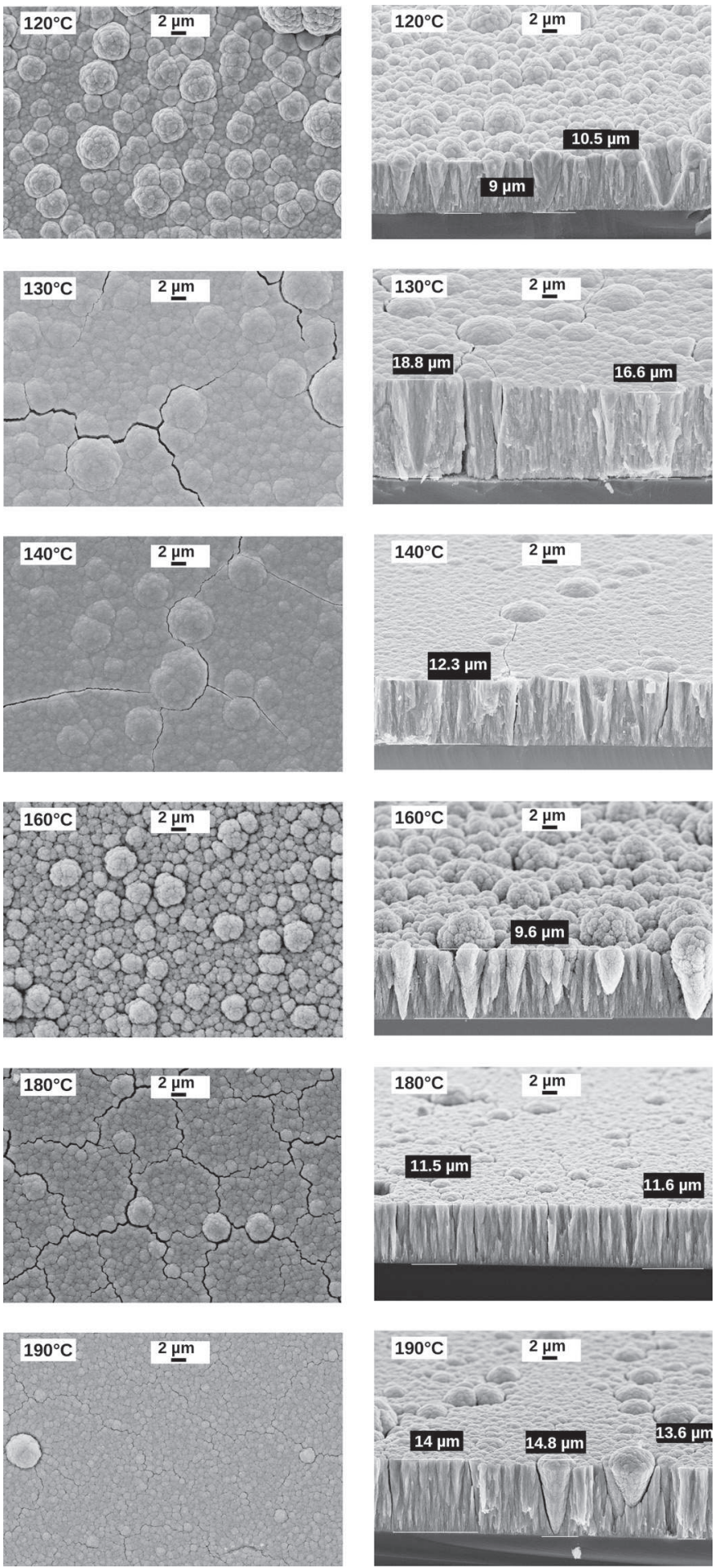

Fig. 3. Top view (left) and cross section (right) SEM images of films deposited under different temperatures. Film thickness $(\mu \mathrm{m})$ is shown at corresponding locations.

a carbonyl precursor, both being catalysts. Thorough investigation of such phenomenon has been attempted in the literature (see for example [40]) but it is outside of the scope of the present work.

Fig. 3 shows SEM images of the CoO films deposited at different temperatures, both in surface view and cross-section view. Films are dense and present a compact columnar structure with a cauliflower morphology which is reproduced at different length scales from $0.05 \mu \mathrm{m}$ at the surface of the grains to $5 \mu \mathrm{m}$ for the larger features diameter. Films processed at $120^{\circ} \mathrm{C}$ and $160^{\circ} \mathrm{C}$ 


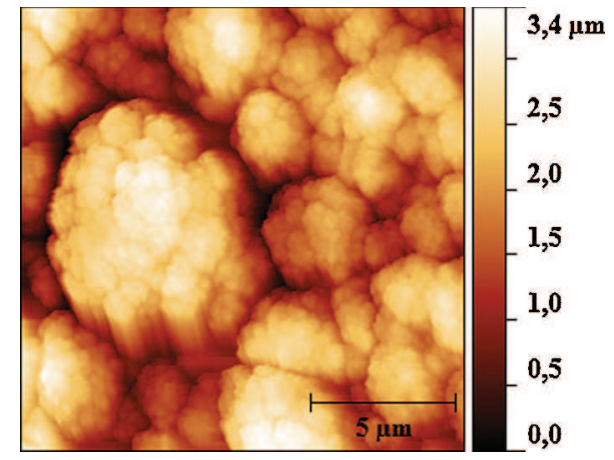

Fig. 4. AFM image of a $\mathrm{CoO}$ coating grown at $160^{\circ} \mathrm{C}$.

present a surface that is more accidental and rougher than the other films, and their columns are wider with a larger conical angle. Interestingly, they correspond to the two minimum growth rates as shown in Fig. 1, and they are the only samples with no visible cracks. Cross section SEM images show that film thickness varies between $9 \mu \mathrm{m}$ and $19 \mu \mathrm{m}$ in agreement with those estimated experimentally by sample mass difference before and after each deposition; a good hint for a limited porosity within the films.

Fig. 4 shows an AFM image of the $160^{\circ} \mathrm{C} \mathrm{CoO}$ film, with the typical cauliflower morphology. It exhibits a root-mean square (RMS) roughness of $c a .350 \mathrm{~nm}$, whereas films grown at $190^{\circ} \mathrm{C}$ show a RMS roughness of $120 \mathrm{~nm}$, only. The difference between the projected surface $\left(400 \mu \mathrm{m}^{2}\right.$ for $160^{\circ} \mathrm{C}$ and $300 \mu \mathrm{m}^{2}$ for $\left.190^{\circ} \mathrm{C}\right)$ and the scanned surface ( $225 \mu \mathrm{m}^{2}$ for both) shows a higher specific area for the sample processed at $160^{\circ} \mathrm{C}$. Interestingly, fractal dimensions determined by the box partitioning method are 2.35 and 2.31, at $160^{\circ} \mathrm{C}$ and $190^{\circ} \mathrm{C}$, respectively; values that equal the natural cauliflower fractal dimension of 2.33 .

Therefore, the present $\mathrm{CoO}$ films exhibit a fractal morphology. The cauliflower shape is repeated identically at different scales, from nano- to micro-. In the literature, only a few groups reported on the formation of $\mathrm{CoO}$ films with a cauliflower structure $[41,42]$. Gupta et al. obtained the cauliflower morphology on electrodeposited films of cobalt-nickel oxide (in the forms of $\mathrm{NiO}$ and $\mathrm{Co}_{3} \mathrm{O}_{4}$ ) with a typical thickness of about $10 \mu \mathrm{m}$ [42]. Alternatively, different fractal structures of cobalt oxide $\left(\mathrm{CoO}\right.$ and $\left.\mathrm{Co}_{3} \mathrm{O}_{4}\right)$ thin films have been synthesized by using laser CVD at room temperature and atmospheric pressure. Size and morphology of the structures can be tailored by the laser irradiation time and the gas flow ratio [43]. A two-step process can also be used in order to obtain a porous and fractal surface morphology, where smooth metallic cobalt surface are first formed by PEMOCVD and then post-treated in an $\mathrm{O}_{2}$ plasma [44]. The above-mentioned deposition techniques provide Co oxide films with targeted cauliflower microstructure. However, unlike above where only some degrees of freedom are technically available, MOCVD allows to obtain the fractal cauliflower morphology with a unique precursor and no reactive gas whatever the deposition temperature is. But we will show below that $T_{\mathrm{d}}$ affects the microstructure, which in turn impacts the reflectivity performance of the films.

In an attempt to perform a statistical analysis of the grain size distribution we use the following procedure. SEM Images at a magnification of $\times 10,000$ are processed at each deposition temperature (Gwyddion freeware [45]). First, a mask is applied on each image by adjusting a slope threshold, taking advantage of the fact that grains visible on the surface are separated by valleys. Therefore the mask floods depressions between grains and underlines surface grain boundaries. In order to assess the consistency of this analysis, four slope thresholds $(7.5 \%, 10 \%, 12.5 \%$ and $15 \%)$ are used; the two maxima being determined visually by the operator. It shows that the

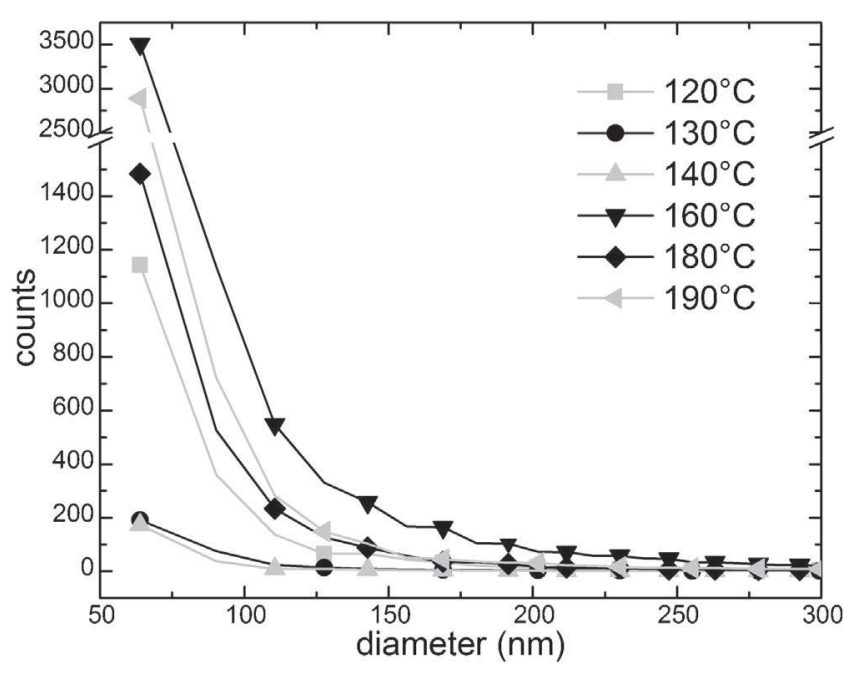

Fig. 5. Grain size distribution (Counts vs. Diameter) for six different deposition temperatures.

trend does not vary, meaning that the temperature dependence of the grain size distribution is constant whatever the slope criterion. Once the mask has been inverted, an equivalent radius is automatically computed for each grain. Then, we perform a frequency analysis to extract the grain size distributions.

Fig. 5 shows the results with a slope threshold fixed at $10 \%$. We observe a classification of grain size distributions. The distribution for films grown at $160^{\circ} \mathrm{C}$ is larger than that at $190^{\circ} \mathrm{C}, 180^{\circ} \mathrm{C}$ and $120^{\circ} \mathrm{C}$, themselves being larger than that $130^{\circ} \mathrm{C}$ and $140^{\circ} \mathrm{C}$. Therefore, within statistical and SEM resolution limits, two main features can be extracted from the grain size distribution analysis. First, each $T_{\mathrm{d}}$ leads to the formation of surface grains with diameters in the range $50 \mathrm{~nm}$ to $\mathrm{ca}$. $200 \mathrm{~nm}$ (in good agreement with the bulk Sherrer analysis of mean crystallites size of 100-150 nm). Secondly, the dispersion of the distribution depends on $T_{\mathrm{d}}$, and the three highest deposition temperatures produce the largest distributions. Hence, surfaces grown at $160^{\circ} \mathrm{C}, 190^{\circ} \mathrm{C}$ and $180^{\circ} \mathrm{C}$ exhibit a relatively larger size distribution of light traps, in the subwavelength light scale, in addition to cauliflowers with diameters up to several micrometers.

\subsection{Optical properties}

Fig. 6 shows the reflectivity spectra of the CoO films processed at different $T_{\mathrm{d}}$. Each spectrum shows a low reflectivity broadband which presents a significant evolution with varying $T_{\mathrm{d}}$. Its position is shifted to longer wavelengths and its width gradually increases with increasing $T_{\mathrm{d}}$ until it covers the whole visible spectral domain at $160^{\circ} \mathrm{C}$ and $180^{\circ} \mathrm{C}$. The $160^{\circ} \mathrm{C}$ and $180^{\circ} \mathrm{C}-\mathrm{CoO}$ films show a rise of their reflectivity at $1050 \mathrm{~nm}$ which corresponds to the band-gap energy of the Si substrate. They exhibit interestingly low [ $400-800 \mathrm{~nm}$ ] average reflectivity of 4.2 and $2.9 \%$, respectively. This observation is comparable with literature results by several groups who deposited either $\mathrm{CoO}$ [41] or $\mathrm{Co}_{3} \mathrm{O}_{4}$ [46] films by electrodeposition techniques for solar absorber applications. Interestingly, the electrodeposited $\mathrm{CoO}(\mathrm{OH})$ films, that result from surface hydration, show a very similar surface microstructure. The reflectivity trend of the film processed at $190^{\circ} \mathrm{C}$ is rather offset compared to the other five films. While it presents a low reflectivity band as well, it is narrow and located at low wavelengths (i.e. $300 \mathrm{~nm}$ ); similar to that of the film processed at $120^{\circ} \mathrm{C}$. The mean value of the reflectivity of this film in the $400-800 \mathrm{~nm}$ domain is largely higher than those of the other films. However, it decreases with increasing wavelength, reaching $\mathrm{ca} .8 \%$ at $1200 \mathrm{~nm}$. Whereas it could represent the most 


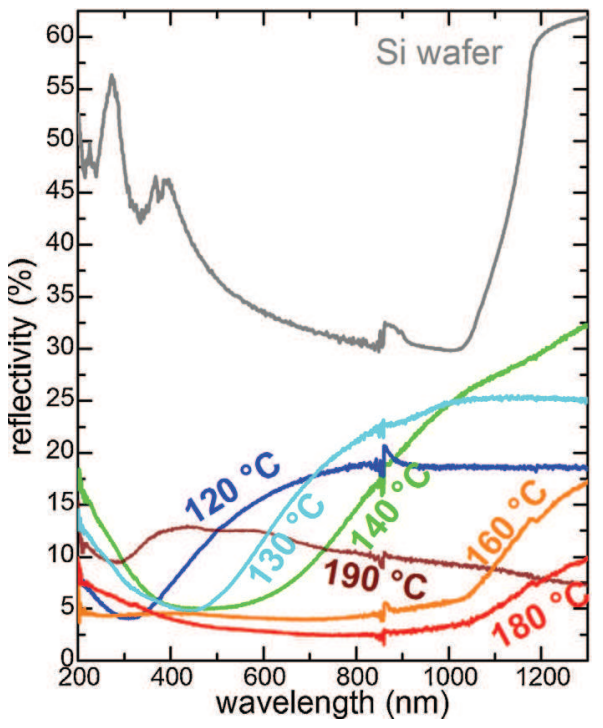

Fig. 6. Reflectivity spectra of $\mathrm{CoO}$ films on $\mathrm{Si}$ wafers for various $T_{\mathrm{d}}$.

appropriate sample for applications in the infrared part of the electromagnetic spectrum, we consider it as an experimental artifact regarding the trend vs. $T_{\mathrm{d}}$.

In the following we discuss possible mechanisms responsible for the low reflectivity, and its evolution with $T_{\mathrm{d}}$.

Since the $\mathrm{CoO}$ films thickness is much higher than the visible wavelengths, and since these films are not composed of nanoscale multilayers stack, we assume that interferences do not affect reflectivity. Besides, spectral features cannot be attributed to interference fringes. Distinct interference fringes could be observed but only for thinner films (not shown here).

Although several studies on $\mathrm{CoO}$ show a band gap of about 5-6 eV $(200-250 \mathrm{~nm})[47,48]$, other groups show that the indirect band gap of $\mathrm{CoO}$ ranges from 2.3 to $2.8 \mathrm{eV}(440-550 \mathrm{~nm})$ $[30,49,50]$. As a result, interband transitions cannot explain the reflectivity of all the spectra. Especially the two lower reflective samples deposited at $160^{\circ} \mathrm{C}$ and $180^{\circ} \mathrm{C}$ show a rise of their reflectivity at noticeably lower energies of $1.2-1.3 \mathrm{eV}(950-1000 \mathrm{~nm})$. However, one cannot totally exclude that transitions at energies lower than the $\mathrm{CoO}$ band gap can occur in our films as reported elsewhere $[47,49]$. And $\mathrm{CoO}$ is effectively studied for its absorption properties for solar thermal absorbers [51], showing that it is able to absorb efficiently in the visible range. Nevertheless, the distinct rise of the reflectivity at the Si band-gap at $1050 \mathrm{~nm}$ of the $160^{\circ} \mathrm{C}$ and $180^{\circ} \mathrm{C}-\mathrm{CoO}$ films demonstrates that the absorption decreases towards NIR wavelengths. The abrupt increase of reflectivity is due to the threshold where the extinction coefficient of $\mathrm{Si}$ becomes null, and where the metallic sample holder contribution increases.

As can been noticed from SEM observation in Fig. 3, the low reflective film deposited at $160^{\circ} \mathrm{C}$ shows a surface with the highest density of micrometric cauliflower grains. But a similar film surface is obtained at $120^{\circ} \mathrm{C}$ whereas it shows the worse visible reflectivity performance. Then, we assume that the $T_{\mathrm{d}}$-dependence of the reflectivity is not due to scattering caused by $\mu \mathrm{m}$-wide cauliflowers: reflectivity is manifestly not correlated to surface density and shape of $\mu \mathrm{m}$-sized cauliflowers. However, light scattering plays a significant role in the reflectivity since the diffuse light reflectivity spectrum overlap almost perfectly with the total reflectivity spectrum (not shown). Therefore, in the absence of a strong correlation between micrometric features surface density and reflectivity, we focus on the evolution of the film structure at the nanoscale.

Taking into account the complex surface microstructure, we can consider a model surface layer made of subwavelength $\mathrm{CoO}$ grains and voids (air). The surface can then be macroscopically considered using the effective medium approximation by a layer whose refractive index is a volume density-weighted average of the two media. Although the refractive index $(n)$ of $\mathrm{CoO}$ single-crystal lies between 1.8 and 2.6 (imaginary part $0.03<k<1.37$ ) in the wavelength range [200-1200 nm] [47], the refractive index of the effective medium at the surface can be significantly lowered because of the contribution of air $(n=1.0)$. Moreover, the likely occurrence of microstructural changes along the columnar structure could result in a rise of the density from free surface towards the bulk. As a consequence, the refractive index of the $\mathrm{CoO}$ films increases with depth. Such films have been first analyzed by Lord Rayleigh [52] who noticed that reflection can be considerably reduced when the transition of the density between two media is gradual. For an infinitely thick nonabsorbing layer, a smooth transition between the refractive index of the incident medium and the refractive index in the bulk of the layer results in reflectivity close to zero according to the Fresnel coefficient [53,54]. For an absorbing layer having a finite thickness, that is greater than the skin depth of the effective medium, the reflectivity is reduced provided that the refractive index at the free surface of the layer is close from the one of the air and also if no sharp modification of the effective refractive index occurs along the skin depth of the layer.

According to this model, we conclude that $T_{\mathrm{d}}$ appears to influence the effective refractive index of the layer probably through the film density. Several authors demonstrate that the widening of the refractive index gradient results in a significant increase of the low reflective broadband width $[54,55]$ similar to our experimental spectra. Other parameters could also influence the refractive index such as the structural configuration of $\mathrm{CoO}$ which varies according to the deposition parameters and/or impurities inclusion in the film. Whatever the cause leading to the modification of the effective index, it results in a significant reflectance response variation with $T_{\mathrm{d}}$.

\section{Conclusions}

We form black CoO films (ca. 50 at.\% Co, 50 at.\% O) on Si by MOCVD from $\mathrm{CO}_{2}(\mathrm{CO})_{8}$ at a working pressure of 5 Torr. We focus on the influence of growth temperature $\left(120-190^{\circ} \mathrm{C}\right)$ on the film microstructure and the resulting optical reflectivity. We form thick (9-18 $\mu \mathrm{m})$ columnar films which exhibit a fractal morphology of cauliflowers, a specificity offered by MOCVD as compared to other deposition techniques. The fractal dimension determined on AFM surface images is $2.31-2.35$; i.e. very close to that of the natural cauliflower (2.33). Optics wise, films are very diffuse and turn black for two peculiar deposition temperatures, 160 and $180^{\circ} \mathrm{C}$, for which reflectivity is the lowest on the whole visible range (2-5\%).

The low reflectivity arises from the peculiar film structures. Since we use a spectrophotometer equipped with an integrating sphere the total reflected light is taken into account in the analysis. Hence, the decrease of the integrated light intensity is due to (i) specular reflectivity (a relatively low refractive index of the effective surface layer material (CoO + voids (air)), (ii) light diffusion, (iii) absorption within the layer, and most likely (iv) a combination of the above-mentioned mechanisms.

The trend of the reflectivity with increasing deposition temperature is assumed to come from a rising refractive index gradient from the air/surface interface towards the bulk of the $\mathrm{CoO}$ coating. The coatings show a columnar structure with a conical geometry whose surface is assumed to be an effective medium of $\mathrm{CoO}+$ voids (air) (with $n$ « 2.2). Hence, we assume that there is a refractive index gradient from the surface layer towards deeper coordinates where the film gets denser, and consequently closer to $n_{\mathrm{COO}}=2.2$. This gradient is responsible for the broadband of low reflectivity observed 
on the spectra. It is somehow linked to the microstructure of the films but we are not successful in the classification of the structures with $T_{\mathrm{d}}$ (mainly because $190^{\circ} \mathrm{C}$ shows an unclear reflectivity behavior making this classification too speculative).

\section{Acknowledgments}

The DIRECCTE Midi-Pyrénées is acknowledged for financial support in the framework of the AEROSAT 2012 program, under contract $n^{\circ} 43186$.

\section{References}

[1] H. Kaplan, Black coatings are critical in optical design, Photon Spectra 31 (1997) 48-50.

[2] H. Shi, J.G. Ok, H.W. Baac, L.J. Guo, Low density carbon nanotube forest as an index-matched and near perfect absorption coating, Appl. Phys. Lett. 99 (2011) 211103.

[3] Y. Goueffon, L. Arurault, C. Mabru, C. Tonon, P. Guigu, Black anodic coatings for space applications: study of the process parameters, characteristics and mechanical properties, J. Mater. Process. Technol. 209 (2009) $5145-5151$

[4] C.-K. Leong, D.D.L. Chung, Carbon black dispersions as thermal pastes that surpass solder in providing high thermal contact conductance, Carbon 41 (2003) 2459-2469.

[5] C.E. Kennedy, Review of Mid - To High Temperatures Solar Selective Absorber Materials, NREL/TP-520-31267, 2002.

[6] W. Bogaerts, C. Lampert, Materials for photothermal solar energy conversion, J. Mater. Sci. 18 (1983) 2847-2875

[7] K.M. Yousif, B.E. Smith, Investigation of microstructure of molybdenum-copper black electrodeposited coatings with reference to solar selectivity, J. Mater. Sci. 31 (1996) 185-191.

[8] X. Xiao, L. Miao, G. Xu, L. Lu, Z. Su, N. Wang, S. Tanemur, A facile process to prepare copper oxide thin films as solar selective absorbers, Appl. Surf. Sci. 257 (2011) 10729-10736.

[9] D. Kraemer, B. Poudel, H.-P. Feng, J.C. Caylor, B. Yu, X. Yan, Y. Ma, X. Wang, D. Wang, A. Muto, K. McEnaney, M. Chiesa, Z. Ren, G. Chen, High-performance flat-panel solar thermoelectric generators with high thermal concentration, Nat. Mater. 10 (2011) 532-538.

[10] A. Lenert, D.M. Bierman, Y. Nam, W.R. Chan, I. Celanovic, M. Soljacic, E.N. Wang, A nanophotonic solar thermophotovoltaic device, Nat. Nanotechnol. 9 (2014) 126-130.

[11] H.N. Noh, S.Y. Myong, Antireflective coating using a WO3-TiO2 nanoparticle photocatalytic composition for high efficiency thin-film Si photovoltaic modules, Solar Energy Mater. Solar Cells 121 (2014) 108-113.

[12] P. Bermel, M.l. Ghebrebrhan, M. Harradon, Y.X. Yeng, I. Celanovic, J. Joannopoulos, M. Soljacic, Tailoring photonic metamaterial resonances for thermal radiation, Nanoscale Res. Lett. 6 (2011) 549

[13] M. He, R. Chen, Structural and optical properties of CuMnCoOx spinel thin films prepared by a citric acid-based sol-gel dip coating route for solar absorber applications, J. Sol-Gel Sci. Technol. 74 (2015) 528-536.

[14] Z.A. Hamid, A.A. Aala, P. Schmuki, Nanostructured black cobalt coatings for solar absorbers, Surf. Interface Anal. 40 (2008) 1493-1499.

[15] G. McDonald, Preliminary Study of a Solar Selective Coating System Using Black Cobalt Oxide for High Temperature Solar Collectors, 1980, NASA TM-81385 report.

[16] N.D. Ivanova, E.I. Boldyrev, S.V. Ivanov, I.S. Makeeva, Electrochemical synthesis of black cobalt, Russ. J. Appl. Chem. 76 (2003) 1589-1592.

[17] N.A.M. Barakat, M.S. Khil, F.A. Sheikh, H.Y. Kim, Synthesis and optical properties of two cobalt oxides $\left(\mathrm{CoO}\right.$ and $\left.\mathrm{Co}_{3} \mathrm{O}_{4}\right)$ nanofibers produced by electrospinning process, J. Phys. Chem. C 112 (2008) $12225-12233$

[18] E. Barrera, L. Huerta, S. Muhl, A. Avila, Synthesis of black cobalt and tin oxide films by the sol-gel process: surface and optical properties, Solar Energy Mater. Solar Cells 88 (2005) 179-186.

[19] H. Yamamoto, T. Naito, M. Terao, T. Shintani, Nano structure analysis of sputtered thin films consisting of cobalt oxide and soda-lime glass composite, Thin Solid Films 411 (2002) 289-297.

[20] T. Warang, N. Patel, A. Santini, N. Bazzanella, A. Kale, A. Miotello, Pulsed laser deposition of $\mathrm{Co}_{3} \mathrm{O}_{4}$ nanoparticles assembled coating: role of substrate temperature to tailor disordered to crystalline phase and related photocatalytic activity in degradation of methylene blue, Appl. Catal. A: Gen. 423-424 (2012) 21-27.

[21] T.Q. Ngo, A. Posadas, H. Seo, S. Hoang, M.D. McDaniel, D. Utess, D.H. Triyoso C.B. Mullins, A.A. Demkov, Atomic layer deposition of photoactive CoO/SrTiO3 and $\mathrm{CoO} / \mathrm{TiO} 2$ on $\mathrm{Si}(001)$ for visible light driven photoelectrochemical water oxidation, J. Appl. Phys. 114 (2013) 084901.

[22] M.E. Donders, H.C.M. Knoops, M.C.M. van de Sanden, W.M.M. Kessels, P.H.L Notten, Remote plasma atomic layer deposition of Co304 thin films, J. Electrochem. Soc. 158 (2011) G92-G96.
[23] M. Diskus, O. Nilsen, H. Fjellvag, Thin films of cobalt oxide deposited on high aspect ratio supports by atomic layer deposition, Chem. Vapor Depos. 17 (2011) 135-140.

[24] M. Burriel, G. Garcia, J. Santiso, A.N. Hansson, S. Linderoth, A. Figueras, Co304 protective coatings prepared by pulsed injection metal organic chemical vapour deposition, Thin Solid Films 473 (2005) 98-103.

[25] J. Tyczkowski, R. Kapica, J. Łojewska, Thin cobalt oxide films for catalysis deposited by plasma-enhanced metal-organic chemical vapor deposition, Thin Solid Films 515 (2007) 6590-6595.

[26] S. Pasko, A. Abrutis, L.G. Hubert-Pfalzgraf, V. Kubilius, Cobalt (II) b-diketonate adducts as new precursors for the growth of cobalt oxide films by liquid injection MOCVD, J. Cryst. Growth 262 (2004) 653-657.

[27] A.R. Ivanova, G. Nuesca, X. Chen, C. Goldberg, A.E. Kaloyeros, B. Arkles, J. Sullivan, The effects of processing parameters in the chemical vapor deposition of cobalt from cobalt tricarbonyl nitrosyl, J. Electrochem. Soc. 146 (1999) 2139-2145.

[28] F. Fau, F. Maury, Growth and characterizations of Co coatings deposited by MOCVD below $120^{\circ} \mathrm{C}$ using Co2(CO)8, in: 3rd Inter. Symp. on Trends and New Applications in Thin Films, Le Vide, les Couches Minces, vol. 259, Société Française du Vide, Paris, 1991, pp. 95-97.

[29] E. Fuji, H. Torii, A. Tomozawa, R. Takayama, T. Hirao, Preparation of cobalt oxide films by plasma-enhanced metalorganic chemical vapour deposition, J. Mater. Sci. 30 (1995) 6013-6018.

[30] A.U. Mane, S.A. Shivashankar, MOCVD of cobalt oxide thin films: dependence of growth,microstructure, and optical properties on the source of oxidation, J. Cryst. Growth 254 (2003) 368-377.

[31] S. Schmid, R. Hausbrand, W. Jaegermann, Cobalt oxide thin film low pressure metal-organic chemical vapor deposition, Thin Solid Films 567 (2014) $8-13$.

[32] M.E. Gross, K. Schnoes Kranz, D. Brasen, H. Luftman, Organometallic chemical vapor deposition of cobalt and formation of cobalt disilicide, J. Vac. Sci. Technol. B 6 (1988) 1548-1552.

[33] D.X. Ye, S. Pimanpana, C. Jezewski, F. Tang, J.J. Senkevich, G.-C. Wang, T.-M. Lu, Low temperature chemical vapor deposition of Co thin films from Co2(CO)8, Thin Solid Films 485 (2005) 95-100.

[34] J. Lee, H.J. Yang, J.H. Lee, J.Y. Kim, W.J. Nam, H.J. Shin, Y.K. Ko, J.G. Lee, E.G. Lee, C.S. Kim, Highly conformal deposition of pure Co films by MOCVD using Co2(CO)8 as a precursor, J. Electrochem. Soc. 153 (6) (2006) G539-G542.

[35] Y.K. Ko, D.S. Park, B.S. Seo, H.J. Yang, H.J. Shin, J.Y. Kim, J.H. Lee, W.H. Lee, P.J. Reucroft, J.G. Lee, Studies of cobalt thin films deposited by sputtering and MOCVD, Mater. Chem. Phys. 80 (2003) 560-564.

[36] G. Dormans, OMCVD of cobalt and cobalt silicide, J. Cryst. Growth 114 (3) (1994) 364-372

[37] Q. Zhao, D.W. Greve, K. Barmak, UHV/CVD growth of Co on Si(001) using cobalt carbonyl, Appl. Surf. Sci. 219 (2003) 136-142.

[38] H.S. Rhee, B.T. Ahn, Cobalt metallorganic chemical vapor deposition and formation of epitaxial CoSi2 layer on $\mathrm{Si}(100)$ substrate, J. Electrochem. Soc 146 (1999) 2720-2724.

[39] J. Lee, J.G. Lee, Deposition characteristics of Co thin films over high aspect ratio trenches by MOCVD using CO2(CO) 8 as a precursor, J. Korean Phys. Soc. 49 (2006) 697-701.

[40] H. Chen, A.A. Adesina, Improved alkene selectivity in carbon monoxide hydrogenation over silica supported cobalt-molybdenum catalyst, Appl. Catal. A: Gen. 112 (1994) 87-103.

[41] M.G. Hutchins, P.J. Wright, P.D. Grebenik, Comparison of different forms of black cobalt selective solar absorber surfaces, Solar Energy Mater. 16 (1987) 113-131.

[42] V. Gupta, T. Kawaguchi, N. Miura, Synthesis and electrochemical behavior of nanostructured cauliflower-shape Co-Ni/Co-Ni oxides composites, Mater. Res. Bull. 44 (2009) 202-206.

[43] P. Haniam, C. Kunsombat, S. Chiangga, A. Songsasen, Synthesis of cobalt oxides thin films fractal structures by laser chemical vapor deposition, ScientificWorldjournal 2014 (2014) 685270-685276.

[44] G.L. Chen, C. Guyon, Z.X. Zhang, B.D. Silva, P.D. Costa, S. Ognier, D. Bonn, M. Tatoulian, Catkin liked nano-Co3O4 catalyst built-in organic microreactor by PEMOCVD method for trace CO oxidation at room temperature, Microfluid Nanofluid 16 (2013) 141-148.

[45] D. Nečas, P. Klapetek, Gwyddion: an open-source software for SPM data analysis, Cent. Eur. J. Phys. 10 (2012) 181-188

[46] E. Barrera, I. González, T. Viveros, A new cobalt oxide electrodeposit bath for solar absorbers, Sol. Energy Mater. Sol. Cells 51 (1998) 69-82.

[47] T.D. Kang, H.S. Lee, H. Lee, Optical properties of black NiO and $\mathrm{CoO}$ single crystals studied with spectroscopic ellipsometry, J. Korean Phys. Soc. 50 (2007) 632-637.

[48] J.G. Cook, F.P. Koffyberg, Solar thermal absorbers employing oxides of Ni and Co, Sol. Energy Mater. 10 (1984) 55-67.

[49] L. Liao, O Zhang Z. Su, Z. Zhao, Y. Wang Y. Li, X. Lu, D. Wei, G, Feng O Yu, X Cai, J. Zhao, Z. Ren, H. Fang, F. Robles-Hernandez, S. Baldelli, J. Bao, Efficient solar water-splitting using a nanocrystalline $\mathrm{CoO}$ photocatalyst, Nat. Nanotechnol. 9 (2014) 69-73.

[50] R. Gillen, J. Robertson, Accurate screened exchange band structures for the transition metal monoxides $\mathrm{MnO}, \mathrm{FeO}, \mathrm{CoO}$ and NiO, J. Phys.: Condens. Matter 25 (2013) 165502 
[51] A. Amri, Z.T. Jiang, T. Pryor, C.-Y. Yin, S. Djordjevic, Developments in the synthesis of flat plate solar selective absorber materials via sol-gel methods: a review, Renew. Sustain. Energy Rev. 36 (2014) 316-328.

[52] J.S. Rayleigh, On reflection of vibrations at the confines of two media between which the transition is gradual, Proc. Lond. Math. Soc. 11 (1880) 51.

[53] M.F. Schubert, F.W. Mont, S. Chhajed, D.J. Poxson, J.K. Kim, E.F. Schubert, Design of multilayer antireflection coatings madefrom co-sputtered and low-refractive-indexmaterials by genetic algorithm, Opt. Express 16 (2008) 5290-5298.
[54] M. Bass, Optical properties of films and coatings, in: M. Bass (Ed.), Handbook of Optics: Volume IV - Optical Properties of Materials, Nonlinear Optics, Quantum Optics, Third ed., McGraw-Hill Professional, New York, 2010.

[55] F. Guillemot, Couches poreuses de silice structurées par des latex: structure, propriétés mécaniques et applications optiques, Materials chemistry, Ecole Polytechnique X, Paris, 2010, PhD Thesis. 